\title{
Phytochemical screening and evaluation of antidepressant activity of methanolic extract of the spadix of Colocasia affinis Schott
}

\author{
C. Lalremruati*, C. Malsawmtluangi, H. Lalhlenmawia \\ Department of Pharmacy, Regional Institute of Paramedical and Nursing Sciences, Zemabawk 796or7, India
}

\begin{abstract}
The objective of this study was to determine the phytoconstituents present in successive extracts and the antidepressant activity of methanolic extract of the spadix of Colocasia affinis. The preliminary phytochemical investigation indicated the presence of fats and fixed oils, steroids and triterpenoids in petroleum ether extract, steroids and triterpenoids in chloroform extract, flavonoids and tannins in methanol extract and carbohydrates in the aqueous extract. An in vivo test for antidepressant activity was performed on the methanolic extract of the plant at two different doses using force swim test and tail suspension test on an experimental animal model (rat). Imipramine was used as a standard drug for the study. The methanolic extract at 200 and $400 \mathrm{mg} / \mathrm{kg}$, produced significant reduction $(p<0.001)$ in the immobility period when compared with that of control group animals in both the tests. Thus, the result indicates that the methanolic extract exhibited significantly good antidepressant activity. Further investigation may be needed to understand the actual mechanism of action.
\end{abstract}

Keywords: Colocasia affinis, antidepressant, imipramine, phytoconstituents.
Received 16 July 2018 Accepted 22 October 2018

*For correspondence $\bowtie$ : mamechawngthu7@gmail.com

\section{INTRODUCTION}

Plants play a significant role in maintaining human health and in improving the quality of human life since a long time and have served humans well as valuable components of medicines, seasoning, beverages, cosmetics, and dyes. Based on the theory that plants contain natural substances that can promote health and alleviate illness, herbal medicines were used in recent times to cure sickness. Therefore, research on the plant has been a focus all over the world and there is huge evidence which shows the enormous potential of medicinal plants used in various traditional systems. ${ }^{1}$ There is no proper investigation on therapeutic activities of the plant used in the indigenous system of medicine. Today, scientists are using these renewable resources to produce a new generation of therapeutic solutions. ${ }^{2}$

Plants synthesize a large number of novel chemical compounds which offer a huge potential use in medicine and other applications. Plants contain many active compounds such as alkaloids, steroids, tannins, glycosides, volatile oils, fixed oils, resins, phenols and flavonoids which are known to possess immense pharmacological activities, and 
due to these properties they are largely used for medicinal purpose. Identified 119 secondary plant metabolites were used as drugs. Out of 255 drugs which are considered as basic and essential by the World Health Organization (WHO), 11\% are obtained from plants and a number of synthetic drugs are also obtained from natural precursors. Phytochemicals constitute an important source of development of drugs to treat various diseases and has always been a field of speculation for researchers. Therefore, screening of plants for the presence of natural products and beneficial properties formed the basis of drug development. ${ }^{3}$

Depression is a life-threatening psychiatric disorder that affects several millions of the world population. The World Health Organization revealed that depression is the fourth leading cause of disability worldwide, exceeded by lower respiratory infections, perinatal conditions and AIDS. ${ }^{4} \mathrm{Ap}$ proximately, two third of depressed patients experience suicide thoughts and $10-15 \%$ of them attempt suicide. ${ }^{5}$ The main symptoms of depression are due to a functional deficiency in the levels of monoaminergic transmitters noradrenalin, 5hydroxytryptamine and dopamine in the brain. ${ }^{6}$ Drugs that increase the level of these neurotransmitters in the central nervous system show antidepressant activity. ${ }^{5}$ Major antidepressant drugs which are currently used today aimed for an enhancement in the transmitters levels in the neurons and thus normalize the neurotransmission which has proven to be effective. ${ }^{7}$ However, they are known to cause various adverse effects, problematic interactions and relatively low response. Therefore, much efforts and investments have been made for finding the cure by using traditional medicines because of their substantially low side effects. ${ }^{8}$

The main purpose of the present study was screening of Colocasia affinis Schott for the presence of various phytochemicals and evaluation of antidepressant activity of methanolic extract of its spadix. C. affinis ("baibing" in Mizo), belonging to the family Araceae, is a many-nerved, broad leaved perennial herb; petiole is slightly pink. It grows in an altitude below $900 \mathrm{~m}$. Flowers and fruits are mainly produced during June to August. In Mizoram, it is mainly found in new jhum land. The spadix and stems are eaten cooked as a vegetable. In Mizo tradition, it is mainly consumed as dish after boiling with water. Traditionally, juice of the plant is used externally for snake bite. The leaf is also used for catching land leech from the body. ${ }^{9}$ In India, the species is commonly known as shola kachu and is widely used in Ayurvedic medicines since time immemorial. Almost all parts of these plants are used as a food. It is also known as poor man's food, primarily due to their richness in starch. Konda Reddis and Savaras tribes use rhizome paste to treat wounds and to kill worms in domestic animals. Kanda and Nuke Doras people also apply the rhizome paste for curing cracks in the heels and wounds. ${ }^{2}$ The leaf is used against tumors. It also acts as a mild laxative and diuretic. ${ }^{10}$

\section{MATERIALS AND METHODS}

\section{Collection of plant material}

The spadix of $C$. affinis was collected from the local market of Aizawl, Mizoram. It was dried under shade to remove moisture with occasional shifting and then powdered with a mechanical grinder. It was then subjected to successive extraction of phytoconstituents using soxhlet apparatus. The plant specimen was authenticated at the Botanical Survey of India, Northeastern Regional Centre, Shillong, India, with an accession number AP/RIPANS/04.

\section{Extraction of phytoconstituents}

The dried powdered materials of spadix of $C$. affinis were defatted with petroleum ether $\left(60-80^{\circ}\right.$ C) and the defatted powdered material thus obtained was further extracted with chloroform and methanol in a Soxhlet apparatus. The extraction was carried out exhaustively and the solvents were recovered by simple distillation. The concentrated extracts were kept in a refrigerator at $4^{\circ} \mathrm{C}$ for further use. 


\section{Chemicals, reagents, and drugs}

Imipramine, Fehling's A and B and glacial acetic acid were obtained from Sigma Aldrich Pvt. Ltd. Methanol, petroleum ether, chloroform, copper sulfate, ferric chloride, and sodium carbonate were purchased from Merck Pvt. Ltd. Other chemicals were also of analytical grade from Himedia or Merck Pvt. Ltd.

\section{Experimental animals}

Both sexes of albino rats weighing approximately 100-200 g were selected for the study. They were maintained in standard laboratory conditions $\left(25 \pm 5^{\circ} \mathrm{C}\right.$ and light/dark cycles, i.e. $\left.12 / 12 \mathrm{~h}\right)$ and fed with standard food and water ad libitum at the Department of Pharmacy, RIPANS. The animals were maintained under standard conditions as per the guidelines of CPCSEA. The study involving the use of these animals had IAEC permission certificate no. IAEC/ RIPANS/16.

\section{Phytochemical screening of C. affinis extract}

Petroleum ether, chloroform and methanol extract of spadix of $C$. affinis were subjected to qualitative analysis to investigate the presence of various phytochemical constituents such as alkaloids, glycosides, fats and fixed oils, phytosterols, proteins, amino acids, saponins, tannins and flavonoids and the aqueous extract for carbohydrates. ${ }^{11}$

\section{Acute oral toxicity study}

Prior to dosing, animals were fasted overnight before being weighed, and all the extracts were orally administered in a single dose by using a feeding needle (Table 1). The volume given was $2000 \mathrm{mg} / \mathrm{kg}$ body weight (body wt.). Following the period of fasting, the fasted body weight of each animal was determined and the dose was calculated according to the body weight. After the extract was administered, food was withheld for a further 3-4 hours. One animal was dosed at the test dose. If the animal dies, the main test should be conducted to determine the LD50. But the animal survives, and four additional animals were dosed sequentially so that a total of five animals are tested. However, if three animals die, the limit test is terminated and the main test is performed.

Wellness parameters: Animals were observed continuously during the first $30 \mathrm{~min}$ after dosing and observed periodically (with special attention given during the first 4 hours) for the next 24 hours and then daily thereafter, for 14 days. All observations were systematically recorded with individual records being maintained for each animal. Observations included changes in skin and fur, eyes and mucous membranes and behavioral pattern. Attention was given for observations of tremors, convulsions, salivation, diarrhea, lethargy, sleep, coma and mortality.

Mortality: The LD50 is greater than $2000 \mathrm{mg} / \mathrm{kg}$ if three or more animals survive. The LD50 is less than the test dose $(2000 \mathrm{mg} / \mathrm{kg})$ when three or more animals die. ${ }^{12}$

\section{In vivo antidepressant activity}

Experimental design for anti-depressant activity: The rats were divided into four groups $(n=5)$. Drugs/vehicle was administered to the animals for seven days.

Group I: Control, received saline $(2 \mathrm{ml} / \mathrm{kg}$ b.w. orally)

Group II: Received standard drug Imipramine (15 mg/kg b.w. orally)

Group III: Received a low dose of methanolic extract (200 mg/kg b.w. orally)

Group IV: Received a high dose of methanolic extract (400 mg/kg b.w. orally)

\section{Forced swim test}

For the forced swim test (FST), rats of either sex were individually forced to swim in an open cylindrical container (diameter $10 \mathrm{~cm}$, height $25 \mathrm{~cm}$ ) containing $19 \mathrm{~cm}$ of water at $25 \pm 1^{\circ} \mathrm{C}$. Treatment was given $60 \mathrm{~min}$ prior to study as described by 
study design. All animals were forced to swim for 6 min and the duration of immobility was observed and measured during the final 4 min interval of the test. Each mouse was judged to be immobile when it ceased struggling and remained floating motionless in the water, making only those movements to keep its head above water. A decrease in the duration of immobility is indicative of an antidepressant-like effect. ${ }^{13}$

\section{Tail suspension test}

The tail suspension method used in this study was similar to those described by Steru et al., (1985). ${ }^{14}$ Treatments was given 60 min prior to study as described by study design. Mice were suspended on the edge of the table, $50 \mathrm{~cm}$ above the floor, with the help of adhesive tape placed approximately $1 \mathrm{~cm}$ from the tip of the tail. The total duration of immobility induced by tail suspension was recorded during a $6 \mathrm{~min}$ of the $10 \mathrm{~min}$ period. The animal was considered to be immobile when it did not show any movement of the body, hanged passively and completely motionless.

\section{Statistical analysis}

All the values were expressed as mean \pm S.E.M. The results were analyzed statistically by one-way ANOVA followed by Tukey's multiple comparison test, $\mathrm{P}<0.05$ was considered significant.

\section{RESULT}

Phytochemical screening of different extracts of $C$. affinis spadix

The preliminary phytochemical screening of different extracts of $C$. affinis spadix was successfully carried out and the results were recorded in Table 1.

\section{Acute oral toxicity study}

The present results show that methanol extract of $C$. affinis spadix did not cause any apparent toxicity in an animal model. No death or signs of toxicity were observed in rats treated with the plant methanol extract at dose $2000 \mathrm{mg} / \mathrm{kg}$ thus establishing its safety in use. Hence, we can conclude that the LD50 is greater than $2000 \mathrm{mg} / \mathrm{kg}$.

\section{In vivo antidepressant activity}

The methanol extract of C. affinis spadix (200 and $400 \mathrm{mg} / \mathrm{kg}$ ) produced significant reduction $(p<0.001)$ in the immobility period when compared with that of control group animals that received only the vehicle in both Forced swim test and Tail suspension test as shown in Table 2 and Figure 1.

Table 1 | Phytochemical screening of petroleum ether, chloroform, and methanol extracts.

\begin{tabular}{|c|c|c|c|c|}
\hline SI. no. & Secondary Metabolites & $\begin{array}{c}\text { Petroleum ether } \\
\text { extract }\end{array}$ & $\begin{array}{c}\text { Chloroform } \\
\text { extract }\end{array}$ & $\begin{array}{c}\text { Methanol } \\
\text { extract }\end{array}$ \\
\hline 1 & Alkaloids & - & - & - \\
\hline 2 & Flavonoids & - & - & + \\
\hline 3 & Proteins and amino acid & - & - & - \\
\hline 4 & Tannins & - & - & + \\
\hline 5 & Fats and fixed oils & + & - & - \\
\hline 6 & Steroids and triterpenoids & + & + & - \\
\hline 7 & Saponins & - & - & - \\
\hline 8 & Glycosides & & - & \\
\hline 9 & Carbohydrates (aqueous) & & + & \\
\hline
\end{tabular}


Table 2 | Effect of methanolic extract of $C$. affinis spadix on immobility time in forced swim test and tail suspension test.

\begin{tabular}{cccc}
\hline Treatment & Dose $\mathbf{( m g / k g )}$ & $\begin{array}{c}\text { Force swim test duration of } \\
\text { immobility }(\mathbf{s e c})\end{array}$ & $\begin{array}{c}\text { Tail suspension test } \\
\text { duration of immobility (sec) }\end{array}$ \\
\hline Control & - & $193.6 \pm 1.860$ & $120 \pm 1.158$ \\
\hline Imipramine & 15 & $136 \pm 1.655^{\mathrm{a}}$ & $83.4 \pm 1.364^{\mathrm{a}}$ \\
\hline Extract low dose & 200 & $177.2 \pm 1.655^{\mathrm{ab}}$ & $95.6 \pm 0.9274^{\mathrm{ab}}$ \\
\hline Extract high dose & 400 & $168.8 \pm 1.562^{\mathrm{ab}}$ & $89.6 \pm 1.208^{\mathrm{ac}}$ \\
\hline
\end{tabular}

Each value represents mean \pm S.E.M., $n=5$,

${ }^{a} p<0.001$ compared with control; ${ }^{b} p<0.001$ compared with standard; ${ }^{c} p<0.01$ compared with standard

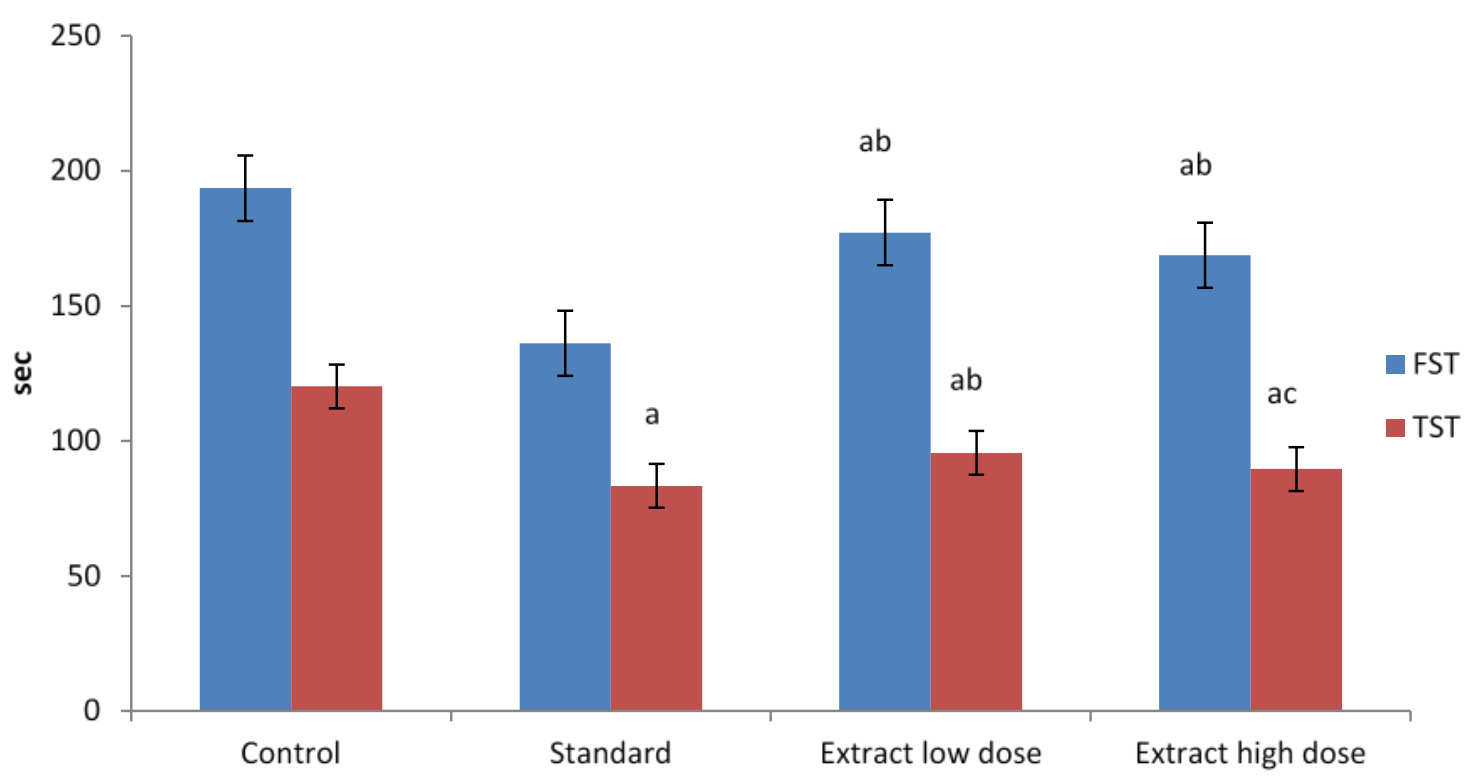

Figure 1 | Effect of methanolic extract of $C$. affinis spadix on immobility time in forced swim test and tail suspension test. Each value represents mean \pm S.E.M., $n=5,{ }^{a} p<0.001$ compared with control; ${ }^{b} p<0.001$ compared with standard; ${ }^{c} p<0.01$ compared with standard

\section{DISCUSSION}

The phytochemical screening shows the presence of secondary metabolites such as fats and fixed oils, steroids and triterpenoids in petroleum ether extract, steroids and triterpenoids in chloroform extract, flavonoids and tannins in methanol extract and carbohydrates in the aqueous extract. These secondary metabolites may be liable to con- tribute toward the biological activities of the plant.

The antidepressant effect of methanolic extract of spadix of C. affinis (200 and $400 \mathrm{mg} / \mathrm{kg}$ ) and imipramine was studied by observing the changes in the duration of immobility in the two models: Forced swim test (FST) and Tail suspension test (TST). These tests are used to monitor depressivelike behavior and are based on the assumption that immobility reflects a measure of behavioral de- 
spair. ${ }^{15}$ In both TST and FST, methanolic plant extract 200 and $400 \mathrm{mg} / \mathrm{kg}$, produced significant reduction $(p<0.001)$ in the immobility period when compared with that of control group animals that received only the vehicle.

The precise mechanisms of the antidepressantlike effect produced by $C$. affinis spadix extract are not completely understood. However, the pattern of behaviors of rats exerted by the extract in the FST from our results is similar to those of imipramine according to Potdar and Kibile, which suggests that this plant extract acts probably by enhancement of norepinephrine neurotransmission as it is related to climbing behavior in the FST. ${ }^{8}$

\section{CONCLUSION}

The phytochemical screening in this study has revealed the presence of secondary metabolites such as fats and fixed oils, steroids and triterpenoids in petroleum ether extract, steroids and triterpenoids in chloroform extract, flavonoids and tannins in methanol extract and carbohydrates in the aqueous extract. The present study also showed that the extract possesses antidepressant effect. As the effect of the extract was similar to that of imipramine, it may be concluded that this effect might be related to the enhancement of norepinephrine neurotransmission. Although further research is required for identifying the unknown bioactive compounds and to establish their pharmacological properties involved in the antidepressant activity of the methanolic extract of $C$. affinis spadix.

\section{Acknowledgement}

The authors are sincerely thankful to Director of RIPANS, Aizawl, India for providing us with necessary facilities to carry out this research work.

\section{REFERENCES}

I. Jayanthi, A., Pritha, C., Papiya, D., Sudeshna, C. \& Bohnisikha C. (2015). Cytotoxicity and antimicrobial activity of Colocasia esculenta. Journal of Chemical and Pharmaceutical Research 7, 627-635.

2. Haque, M., Jahan, T. \& Rashid M.A. (2014). Antibacterial and cytotoxic activities of C. affinis (Roxb.). International Journal of Nutrition, Pharmacology, Neurological Diseases 4, 29-23.

3. Joseph, B.S., Kumbhare, P.H. \& Kale, M.C. (2013). Preliminary phytochemical screening of selected Medicinal Plants. International Research Journal of Science $\mathcal{E}$ Engineering $\mathbf{1}$, 55-62.

4. World Health Organization. (200I). Mental health: new understanding, new hope. In: The World Health Report ( ${ }^{\text {st }}$ ed), France, pp. 29-30.

5. Moallem, S.A., Hosscinzadeh, H. \& Ghoncheh, F. (2007). Evaluation of antidepressant effect of aerial parts of Echium vulgare on mice. Iranian Journal of Basic Medical Sciences 10, I89-196.

6. Meyers, S. (2000). Monoaminergic supplements as natural antidepressants. Alternative Medicine Review s, 64-7I.

7. Jithan, A. \& Chinnalalaiah, R. (2009). Synthesis and evaluation of antidepressant activity of some curcuminlike compounds. InPharm Communique 2, 38-4I.

8. Potdar, V.H. \& Kibile, S.J. (20II). Evaluation of Antidepressant-like Effect of Citrus Maxima Leaves in Animal Models of Depression. Iranian Journal of Basic Medical Sciences 14, 478-483.

9. Sawmliana, M. (2013). The Book of Mizoram Plants (Includes Wild Animals, Birds, etc.) $\left(2^{\text {nd }}\right.$ ed), P. Zakhuma, Aizawl, Mizoram, p. I6.

Io. Ghani, A. (2003). Medicinal Plants of Bangladesh: Chemical constituents and uses. In: Asiatic Society of Bangladesh ( $2^{\text {nd }}$ ed), Dhaka, pp. 71-72.

II. Kokate, C.K., Purohit, A.P. \& Gokhale, S.B. (20I2). Pharmacognosy, $\left(8^{\text {th }}\right.$ ed), Nirali Prakashan, Pune, pp. A.I-A.6.

I2. OECD iLibrary. (2008). Guidelines for the testing of chemicals: Acute Oral Toxicity - Up and Down procedure (UDP). https://read.oecd-ilibrary.org/ environment/test-no-425-acute-oral-toxicity-up-anddown-procedure_9789264071049-en (3 October 2008).

13. Porsolt, R.D., Bertin, A. \& Jalfre, M. (1977). Behavioral despair in mice: a primary screening test for antidepressants. Archives International de Pharmacodynamieet de 
Thérapie 229, 327-336.

I4. Steru, L., Chermat, R., Thierry, B. \& Simon, P. (1985). The tail suspension test: a new method for screening antidepressants in mice. Psychopharmacology (Berl) 85 ,
367-370.

I5. Cryan, J.F. \& Holmes, A. (2005). The ascent of mouse: advances in modelling human depression and anxiety. Nature Reviews Drug discovery 4, 775-790. 